\title{
When and why are the elderly medical patients admitted and readmitted?
}

\author{
Donna L Wolff ${ }^{*}$, Christian B Mogensen ${ }^{2}$ \\ From 6th Danish Emergency Medicine Conference \\ Odense, Denmark. 20-21 November 2014
}

\begin{abstract}
Background
Acute hospitalizations of elderly people are increasing, resource-demanding, and potentially harmful. There is an ongoing interest in alternatives to admissions and in reducing the length-of-stay. Before suggesting alternatives more knowledge is requested, especially concerning admission patterns and whether short stay is associated with increased risk of re-admission. The aim was to describe the acute medical (re)admission patterns in patients more than 65 years old.
\end{abstract}

\section{Methods}

A retrospective cohort study included all $65+$ years acute medical admissions between April 2012 - February 2014 in 3 hospitals of Southern Jutland. Data about patient and hospital characteristics was analyzed using logistic regression. Primary admission was defined as no previous admission within the last 30 days and readmission as less than 30 days since last admission.

\section{Results}

Preliminary results showed that among $65+$ years 15,714 acute medical admissions accounted for $37 \%$ of all acute adult hospital admissions. The median age was 78 years (q25-q75: 71-84 years) equally gender distributed. The admission rate was significantly higher in January and July (9\%) and lower in April (7\%) than the average months $(\mathrm{p}<0.0001)$. Monday and Friday had the highest and Saturday and Sunday the lowest admission $(16 \%$ vs $11 \%, \mathrm{p}<0.0001) .81 \%$ were admitted between $8 \mathrm{am}$. and $21 \mathrm{pm}$. Median length-of-stay was 2.7 days (q25-q75: 0.9 - 6.3 days). $44 \%$ were discharged within 48 hours and only $22 \%$ stayed for more than 1 week. $19 \%$ of the admissions were readmissions, $16 \%$ after a primary admission.

\footnotetext{
* Correspondence: Donna.wolff@rsyd.dk

${ }^{1}$ Medical Center, Hospital of Southern Denmark, Aabenraa, Denmark

Full list of author information is available at the end of the article
}

There was a significant lower readmission rate after short versus long (<> 48 hours) primary admissions (13\% vs. $18 \% \mathrm{p}<0.0001)$. Increased risk for readmission was also related to gender and month of admission, but not to the patient's municipal, triage, age, diagnosis, hospital, department shifts, weekday, or time of primary admission.

\section{Conclusions}

Medical acute admissions among elderly account for more than $1 / 3$ of all acute admissions among adults and occur mainly during daytime. 19\% are readmissions, and the risk of readmission were not associated to short in-hospital stay, age, municipal, or discharge diagnosis but to month of admission and gender.

\section{Authors' details}

${ }^{1}$ Medical Center, Hospital of Southern Denmark, Aabenraa, Denmark. ${ }^{2}$ Emergency Center, Hospital of Southern Denmark, Aabenraa, Denmark.

Published: 16 July 2015

doi:10.1186/1757-7241-23-S1-A56

Cite this article as: Wolff and Mogensen: When and why are the elderly medical patients admitted and readmitted? Scandinavian Journal of Trauma, Resuscitation and Emergency Medicine 2015 23(Suppl 1):A56.

Submit your next manuscript to BioMed Central and take full advantage of:

- Convenient online submission

- Thorough peer review

- No space constraints or color figure charges

- Immediate publication on acceptance

- Inclusion in PubMed, CAS, Scopus and Google Scholar

- Research which is freely available for redistribution 